Revisão

\title{
Enforcement Anticorrupção e Organizações: Uma Revisão Narrativa
}

\author{
Anti-Corruption Enforcement and Organizations: A Narrative Review
}

\author{
Robson Fernandes Soares*1 $\odot$ \\ Edson Ronaldo Guarido Filho' ${ }^{\circ}$
}

\section{RESUMO}

Contexto: na literatura de administração é possível identificar diversas apariçóes do termo enforcement, principalmente relacionadas aos estudos de corrupção. Essas mençóes, contudo, não são uniformes e muitas vezes dizem respeito a tipos diferentes do fenômeno. Além disso, elas ocorrem sem conexão com estudos de regulação, na qual o enforcement é conceito central. Objetivo: o objetivo do presente estudo é identificar os tipos de enforcement anticorrupção presentes na literatura de administraçáo à luz da literatura de regulação. Métodos: foi realizada análise temática reflexiva de 31 artigos da área de administraçáo selecionados na base de dados Web of Knowledge publicados até 2017 nos quais corrupçáo e enforcement aparecem de forma relacionada. Resultados: ao término da análise foi possível identificar quatro tipos de apariçáo do termo na literatura: enforcement punitivo, de mercado, competitivo e cultural. Esses quatro tipos apresentam características únicas à luz da literatura de regulação. Conclusóes: a identificação dos tipos de enforcement anticorrupção contribui para a diferenciaçáo das diversas formas em que o termo é empregado na literatura. Além disso, como estudo de natureza tipológica, oferece caminho para o desenvolvimento de novas teorias, bem como para a realização de estudos empíricos.

Palavras-chave: enforcement; corrupção; organizações.

\section{ABSTRACT}

Context: in the administration literature, it is possible to identify several occurrences of the term enforcement, mainly related to studies of corruption. These mentions, however, are not uniform and often refer to different types of the phenomenon. In addition, they occur without connection to regulation studies, in which enforcement is a central concept. Objective: the objective of the present study is to identify the types of anticorruption enforcement present in the administration literature in the light of the regulatory literature. Methods: we carried out a reflective thematic analysis on 31 articles in the administration area, selected in the Web of Knowledge database and published until 2017, in which corruption and enforcement appear in a related way. Results: at the end of the analysis, it was possible to identify four types of occurrence of the term in the literature: punitive, market, competitive, and cultural enforcement. These four types have unique characteristics in the light of the regulatory literature. Conclusions: the identification of types of anti-corruption enforcement contributes to differentiate the many ways in which the term is used in the literature. Furthermore, as a study of a typological nature, it offers a way to develop new theories, as well as to carry out empirical studies.

Keywords: enforcement; corruption; organizations.
* Autor Correspondente.
1. Universidade Positivo, Programa de Mestrado e Doutorado em Administração, Curitiba, PR, Brasil.

Como citar: Soares, R. F., \& Guarido Filho, E. R. (2021). Enforcement anticorupção e organizações: Uma revisão narrativa. Revista de Administração Contemporânea, 25(6), e190149. https://doi.org/10.1590/1982-7849rac2021 190149.por
Classificação JEL: D73, K42, N16. Editor-chefe: Wesley Mendes-da-Silva (Fundação Getulio Vargas, EAESP, Brasil) (c) Pareceristas: Silvio Eduardo Alvarez Candido(Universidade Federal de São Carlos, DEP, Brasil) (1) George Rossi (Universidade de São Paulo, EACH, Brasil) [0 Um dos indivíduos revisores optou por não ter sua identidade divulgada. Relatório de Revisão por Pares: O Relatório de Revisão por Pares está disponivel neste link externo. Recebido: $26 / 04 / 2019$ Última versão recebida em: 21/09/2020 Aceite em: 22/09/2020

\begin{tabular}{|c|c|c|c|c|c|c|c|c|c|}
\hline & 1 & 2 & 3 & 4 & 5 & 6 & 7 & 8 & 9 \\
\hline $1^{a}$ rodada & 里 & (x) & (x) & (x) & (x) & $x$ & 电 & $\stackrel{9}{2}$ & \\
\hline $2^{a}$ rodada & (x) & $\stackrel{9}{2}$ & $\stackrel{9}{2}$ & & & & & & \\
\hline $3^{a}$ rodada & $\stackrel{9}{2}$ & & & & & & & & \\
\hline
\end{tabular}




\section{INTRODUÇÃO}

Em estudos da área de administração é possível identificar diversos paradigmas de análise, muitos com pressupostos inteiramente opostos (Burrel, 2006). Essa diversidade de paradigmas pode ser atribuída à própria formação do pensamento em administração, que, como ciência aplicada, inspira-se em modelos de outras ciências, como economia, sociologia e psicologia. Em muitos casos os paradigmas teóricos dessas ciências se mostram compatíveis, mas em outros, há verdadeiro conflito (Gioia \& Pitre, 1990).

Uma das incongruências entre paradigmas está na própria forma como eles entendem determinados termos, que assumem sentidos muito diversos a depender do referencial teórico e epistemológico implícito (Shepherd \& Challenger, 2013). Essa situação começa a ser problemática quando há o uso indiscriminado e não situado de um mesmo termo para referir-se a situaçóes distintas, ocasionando ambiguidades.

Essas ambiguidades são recorrentes na literatura de administração, sendo, não raro, a causa de confusōes conceituais, caracterizadas pela construção de quadros teóricos com conjugação indiscriminada de termos pertencentesa diversaslinhas teóricas (Matitz \&Vizeu, 2012). Um caso particular dessa situação pode ser observado em estudos de administração relacionados ao enforcement ${ }^{1}$.

Em alguns trabalhos, enforcement é empregado como o grau de importância que os indivíduos atribuem às normas (Vitell \& Hidalgo, 2006). Em outros, o enforcement é associado a organismos de controle que atuam sobre as organizações (Jia, Ding, Li, \& Wu, 2009). Há também quem associe enforcement a litígios ou conflitos exercidos em desfavor das empresas (Bakos \& Dellarocas, 2011). Por fim, também há referências a açóes corretivas para remediar os problemas de transaçóes (Mooi \& Gilliland, 2013).

Além dessa diversidade de usos do termo, é possível encontrar abordagens fundamentadas em paradigmas opostos. Há trabalhos que tratam o enforcement em uma lógica utilitarista, concebendo-o como mecanismo punitivo de coação do indivíduo (Becker, 1968); já outros trabalhos concebem o enforcement dentro de uma lógica construtivista, como mecanismo capaz de fomentar mudanças comportamentais através de alteraçóes no modelo mental dos agentes (Fisman \& Miguel, 2007). Em função disso, mostra-se como questão relevante distinguir os tipos de enforcement de normas legais ou sociais, bem como as lógicas de ação associadas a cada tipo (Kaczmarek \& Newman, 2011).

Uma área fértil para estudar as diversas apariçóes do termo são os estudos de administração relacionados à corrupção. Isso porque o fenômeno recente de combate à corrupção tem implicado uma proliferação normativa tanto internacionalmente (Carr, 2007) como nacionalmente (Carson \& Prado, 2014) que tem tido dificuldades de resultar em efeitos práticos efetivos (Heeks \& Mathisen, 2012). Essa dificuldade tem impulsionado estudos que buscam alternativas mais eficazes para o enforcement anticorrupção (Batory, 2012). Essa busca faz com que o termo enforcement seja recorrentemente explorado nas mais diversas abordagens pelos trabalhos acadêmicos.

$\mathrm{Na}$ literatura não foi encontrado trabalho que sistematizasse e tipificasse as diferentes apariçóes do enforcement anticorrupção. Tampouco foi encontrado trabalho que relacionasse essas apariçóes do termo à literatura de regulação, na qual o enforcement é conceito central. Visando a investir nessa lacuna, o presente trabalho tem como objetivo identificar os tipos de enforcement anticorrupção presentes na literatura de administração à luz da literatura da regulação. A relevância desse tipo de trabalho encontra-se em sistematizar o conhecimento, elucidar diferentes pressupostos de cada emprego do termo e subsidiar desenvolvimentos teóricos e empíricos de trabalhos futuros.

Para tanto, inicialmente é realizado o resgate das discussões sobre enforcement na literatura de regulação, na qual o termo tem origem. São apresentados os dois modelos paradigmáticos da literatura (coerção versus persuasão) e, em seguida, são discutidos os refinamentos que levaram às tipologias de enforcement dessa área. Em seguida, são realizadas consideraçóes sobre a corrupção e o movimento anticorrupção nas organizações, bem como sobre os estudos tipológicos em administração. $\mathrm{O}$ trabalho segue apresentando os procedimentos metodológicos para seleção da literatura e realização da análise temática de natureza compreensiva. $\mathrm{Na}$ continuaçáo, são apresentados os quatro tipos de enforcement identificados na literatura e é realizada a contextualização desses tipos à luz da literatura de regulação. Por fim, é apresentada a discussão geral, em que é realizada breve síntese do trabalho e são apresentadas contribuiçóes do presente artigo para estudos futuros.

\section{REVISÃO TEÓRICA}

O termo enforcement não é utilizado de forma uniforme na literatura de regulação. Ora ele é empregado para referir-se às açóes do agente de controle para garantir conformidade ao padrão de conduta desejado, ora como os mecanismos que levam determinados agentes sociais a adotarem certos comportamentos em conformidade com padrão de conduta (Kagan, 1989; May \& Burby, 1998). No presente trabalho, em função de sua amplitude conceitual, é adotada a segunda acepçáo do termo, em que o enforcement é entendido como o processo que induz à conformidade 
com uma norma, podendo ser ela moral ou legal, escrita ou implícita. Nas seçóes que seguem são apresentadas as principais discussōes da área de regulação, segundo a perspectiva aqui empregada. São, ainda, apresentadas considerações sobre o movimento anticorrupção nas organizaçōes e sobre estudos tipológicos em administração.

\section{Comportamento do agente e estratégias de enforcement}

Os estudos sobre regulação têm se fundamentado em dois tipos de estratégias de enforcement: (a) estratégia de coerção; e (b) estratégia de persuasão. Os estudos sobre coerção têm como base a imposição de sanções para inibir a violação de uma norma, enquanto os estudos sobre persuasão buscam em ações de educação, negociação e cooperação o meio para garantir a conformidade (Frank, 1984).

É possível atribuir essas diferenças de abordagem aos pressupostos quanto à natureza humana que os teóricos de cada linha adotam. Na linha coercitiva pressupóemse agentes racionais e, portanto, a decisão de obedecer a uma norma é resultado de um cálculo de maximização da utilidade, em que o agente considera exclusivamente os benefícios e prejuízos da desobediência para tomar sua decisão (Polinsky \& Shavell, 2000). De outro lado, há a abordagem construtivista, que entende que os agentes sociais não desobedecem a uma norma necessariamente de forma intencional e racional, mas por outras razôes, tais como ambiguidade da própria norma, não internalização dos valores normativos ou mesmo desconhecimento (Voermans, 2014).

$\mathrm{Na}$ abordagem coercitiva se aplica a lógica de que o agente agirá em conformidade com uma norma sempre que os custos potenciais da desobediência forem superiores aos ganhos obtidos com a infração (Gunningham, 2010). Assim, basicamente, a abordagem consiste em criar penalidades elevadas o suficiente e com taxas de detecção adequadas de modo que a violação de uma norma se torne economicamente irracional do ponto de vista utilitarista (Cohen, 2000).

Por outro lado, na vertente construtivista é argumentado que os agentes buscam a conformidade seja por haver um senso de responsabilidade social e de aderência aos padróes morais vigentes, seja por estarem sujeitos a fatores externos como forças de mercado, imagem ou obrigações com terceiros (Rechtschaffen, 1997). Nesse sentido, açóes de auto-enforcement, nas quais os agentes buscam identificar e corrigir seus próprios desvios, são uma demonstração do desejo de conformidade com os padróes normativos do ambiente (Helland, 1998). Dessa forma, o objetivo do enforcement é fazer com que seja internalizada no modelo mental do agente a necessidade de conformidade com a norma, independentemente das punições pecuniárias envolvidas (Glicksman \& Earnhart, 2006).

A literatura é vasta sobre os efeitos do enforcement coercitivo para coibir comportamentos que desviem de um padrão de conduta (Gray \& Shimshack, 2011). Já em relação aos efeitos de enforcement persuasivo, há uma quantidade menor de trabalhos empíricos, havendo menos evidências quanto à forma pela qual essa abordagem se mostra efetiva (Earnhart \& Glicksman, 2015). Por outro lado, argumenta-se que um enforcement coercitivo muito forte pode desencadear um processo de resistência, fazendo com que a intençâo de conformidade voluntária seja cada vez menor (Kirchler, 1999). Em função disso, em certas situaçóes, o enforcement coercitivo assume a forma de um $\mathrm{U}$ invertido, gerando efeitos positivos à medida que aumenta, mas danosos quando ultrapassa um limite máximo tolerável (Liu, Van Rooij, \& Lo, 2018).

\section{Tipologias de enforcement}

A discussão entre enforcement coercitivo e persuasivo passou a ser encarada pela literatura como dois extremos em um contínuo que abarcava uma diversidade de estilos, com características tanto de coerção quanto de persuasão (Gormley, 1998). Foram propostos pela literatura diversos refinamentos dessa discussáo inicial que acabaram gerando distinçôes interessantes para compreender o fenômeno. Duas delas são as mais recorrentes e por isso são tratadas aqui. São as distinçóes entre enforcement público e privado e entre enforcement formal e informal. Uma discussão mais detalhada de outras formas de classificação pode ser encontrada em Liu, Van Rooij e Lo (2018) e McAllister (2010).

$\mathrm{O}$ enforcement formal está baseado em mecanismos legais de controle, já o enforcement informal está baseado em mecanismos sociais de controle (Armour, 2008; Frank, 1984). O enforcement público é aquele realizado por um agente governamental, enquanto o enforcement privado é aquele realizado por um agente pertencente ao mercado (Hay \& Shleifer, 1998). Embora seja possível estabelecer paralelos entre a abordagem coercitiva e o enforcement formal e público e entre a abordagem persuasiva e enforcement privado e informal, essas classificações não são dependentes.

$\mathrm{Na}$ abordagem formal, busca-se a criação de incentivos ou inibições em leis ou regras formais, de modo que a existência e aplicação desses mecanismos servem como indutor do comportamento (Galbiati \& Vertova, 2014). Por outro lado, muito da coesão social não vem de aplicação de leis, mas da força exercida por mecanismos informais de enforcement social. Esses mecanismos informais podem ser punitivos, como fofocas negativas e ostracismo, ou recompensadores, tais como estima, reputação ou melhores oportunidades de negociação (Ellickson, 1998). 
Esse tipo de enforcement social é garantido pela interaçáo repetida dos agentes, em que por meio de processos de socialização, comportamentos cooperativos são induzidos e internalizados (Posner, 2002). A interação repetida é importante porque há um aprendizado em relação ao comportamento passado, assim como há a possibilidade de aplicação de represálias ao comportamento oportunista, o que não é possível em interaçôes de apenas um único evento.

Ainda, há uma interação entre os mecanismos formais e informais, uma vez que a aplicação de regras formais, se mal desenhadas, pode afetar a dinâmica do enforcement social e induzir ao conflito (Kube \& Traxler, 2011). Assim como a tipologia puniçáo/persuasáo atua em um contínuo, a formalidade dos mecanismos também varia, com regras rígidas em um extremo, passando por princípios orientadores, até chegar ao outro extremo com inexistência de regras escritas.

A outra discussão entre enforcement público e privado está relacionada à capacidade dos agentes privados de resolver ou não seus conflitos de forma adequada sem intervenção estatal. Em geral, argumenta-se a favor do enforcement público - em primeiro lugar, alegando ser economicamente inviável para uma instituição privada manter um sistema processual e executório das normas, e, em segundo lugar, por haver uma concepção de que o uso da força é exclusividade do Estado (Polinsky \& Shavell, 2007). Vale dizer que essa concepção é, contudo, muito associada à perspectiva punitiva do enforcement.

Por outro lado, também há argumentos a favor de enforcement privado. Para tanto, alega-se que instituições não governamentais apresentam menos entraves burocráticos na execução, além de que são financiadas com recursos privados, portanto, não onerando o orçamento público (Burbank, Farhang, \& Kritzer, 2013). Além disso, o sistema privado de enforcement poderia submeter-se à competição, e dessa forma ser menos suscetível à captura regulatória (Garoupa \& Klerman, 2010).

Esse enforcement privado pode ser executado por entidades privadas independentes, como no caso de câmaras de arbitragem, entidades de certificaçáo e sindicatos (Hay \& Shleifer, 1998). Mas também pode ser decorrente de mecanismos internos à organização como conselho de administração e órgãos de governança. Essa concepção de enforcement privado interno guarda certa relação com a ideia de governança corporativa (Williamson, 1996).

Embora tradicionalmente se vincule o enforcement público a uma dimensão formal e o enforment privado a uma atuação informal, essa associação não é verdadeira, pois há mecanismos de enforcement público que são informais, como também há mecanismos formais de atuação do enforcement privado (Armour, 2008). Da mesma forma, também é possível conceber essa dualidade em um contínuo, que varia de uma atuação exclusivamente estatal, passando por um enforcement misto, até um enforcement exclusivamente realizado no âmbito da esfera privada.

No quadro a seguir é possível realizar uma síntese das principais dimensóes trazidas pela literatura de enforcement. Essas características nem sempre aparecem bem delineadas em estudos que tratam da temática.

Tabela 1. Tipologias de enforcement.

\begin{tabular}{ccc}
\hline Dimensão & Descrição & Contínuos dos tipos ideias \\
\hline Estratégia & Qual o mecanismo de atuaçáo? & Coercitivo $\leftarrow \rightarrow$ Persuasivo \\
Agente & Quem é responsável? & Público $\leftarrow \rightarrow$ Privado \\
Relaçáo & Quão flexível é a aplicação? & Formal $\leftarrow \rightarrow$ Informal \\
\hline
\end{tabular}

Nota. Fonte: elaboração própria.

Essas tipologias permitem estabelecer os principais aspectos envolvidos na configuração dos mecanismos de enforcement. Nesse sentido, quanto ao responsável (agente) pelo enforcement, pode ser ele um agente público, um agente privado ou um misto desses dois. Quanto à abordagem (estratégia) que esse agente pode utilizar para induzir ao enforcement, pode adotar-se orientaçáo exclusivamente punitiva, exclusivamente persuasiva ou que combine tanto aspectos de punição quanto de persuasão. Por fim, a implementação (relaçâo) dessa estratégia pode ser através de uma estrutura de atuação formal, informal, ou com aspectos que conjuguem esses dois pontos.

\section{Corrupção e movimento anticorrupção em organizações}

Antes de discutir as aparições de enforcement na literatura anticorrupção, cabe realizar uma breve contextualização da corrupção e do movimento anticorrupção em organizaçóes. A corrupção tem sido apontada pela 
literatura como sendo prejudicial e disfuncional para a sociedade, constituindo um problema social amplo (Torsello \& Venard, 2016). As consequências negativas da corrupção, contudo, não se limitam apenas ao plano social. Estudos da área de administração têm analisado os efeitos deletérios da corrupção também para as organizações. Entre possíveis consequências que ela pode trazer para as empresas, cabe citar os danos à reputação, os riscos de punição, a perda da competitividade, os custos de transação e ainda a criação de uma cultura organizacional antiética (Luo, 2005). Em função disso, a literatura de negócios também tem associado a corrupção a uma conotaçáo negativa, rotulando-a de lado negro das organizações (Linstead, Maréchal, \& Griffin, 2014).

A necessidade de lidar com esses aspectos negativos para as organizaçōes tem fomentado uma crescente literatura tanto sobre corrupção nas empresas como sobre esforços anticorrupção organizacional (Pertiwi, 2018). Os trabalhos têm focado tanto na compreensão da corrupçáo ao nível do indivíduo organizacional (plano micro) quanto na corrupção disseminada na estrutura organizacional (plano macro) (Ashforth, Gioia, Robinson, \& Trevino, 2008). As evidências têm mostrado que esses dois aspectos não somente são correlacionados como geram impactos negativos no desempenho organizacional (Katou, 2013).

Para melhor combater esses malefícios, os trabalhos têm buscando entender os fatores que contribuem para a ocorrência da corrupção. Esses fatores são classificados como internos ou externos à organização (Pinto, Leana, \& Pil, 2008). Entre as causas internas podem-se citar estrutura de incentivos, cultura agressiva, ausência de controles (Galang, 2012). Entre as causas externas estão a estrutura de competição da indústria, regulação, pressóes institucionais (Luo, 2005).

Em função dessas múltiplas causas, múltiplas respostas têm sido propostas, tais como mudanças regulatórias, endurecimento da aplicaçáo legal, incentivos para adoçáa de sistemas de controle anticorrupçáo, entre outras (Osuagwu, 2012). Contudo, muitas dessas mudanças, principalmente as decorrentes de atuação estatal, têm se mostrado inócuas, muitas vezes por desconsiderar as dinâmicas dos mecanismos de controle ou por esbarrarem em limitaçóes orçamentárias (Heeks \& Mathisen, 2012).

Felizmente, a literatura de administração tem contribuído para a proliferação de estudos que abordam mecanismos anticorrupção multidimensionais. Nesse sentido, são estudados mecanismos de controle formais, informais, focados em processos ou em resultados e que consideram diversos agentes de interesse (Lange, 2008). Cabe notar que nesses estudos permeia também a discussão sobre enforcement organizacional, motivo pelo qual essa literatura é rica para entender tal fenômeno.

\section{Tipologias em administração}

As tipologias têm sido importantes na literatura de administração como caminho para o desenvolvimento de teorias organizacionais (Delbridge \& Fiss, 2013). Isso acontece porque teorias possuem como propósito a descrição, explicação e predição de fenômenos, e as tipologias encontram lugar como ferramentas úteis tanto para descrever quanto para explicar fenômenos (Snow \& Ketchen, 2014). Nesse sentido é possível citar diversas teorias organizacionais que tiveram origem em estudos tipológicos, como a teoria da vantagem competitiva de Porter (1980), fundamentada nos tipos ideais de estratégias, e a teoria das estruturas organizacionais de Mintzberg (1979), ancorada nos tipos ideais de estrutura organizacional.

Nesse ponto, cabe mencionar que tipologias não são meros esquemas de classificação. Esquemas de classificação são regras de decisão que têm como função categorizar fenômenos em categorias mutuamente excludentes e de forma exaustiva. Já tipologias, ao contrário, não oferecem regras de decisão, mas sim tipos ideais de fenômeno, que descrevem uma combinação de atributos (Doty \& Glick, 1994). Em função disso, tipologias são baseadas em lógicas de consistência, isto é, elas geralmente são construídas e avaliadas na noçáo de 'ajuste' entre as diferentes partes que compóem o tipo ou configuração ideal (Fiss, 2011). Em função disso, tipologias apresentam maior grau de abstração.

Esse maior grau de abrangência e abstração, contudo, não as transforma em teorias, pois não cabe às tipologias responder a questôes como por quê, como, de que forma (Bacharach, 1989). Por outro lado, as tipologias constituem ponto de partida para construçóes de teorias, uma vez que a partir delas podem ser propostas relaçóes teóricas, formuladas hipóteses, desenvolvidas métricas e testadas relaçóes. Assim, tipologias consistem em excelente ferramenta tanto para discutir teorias já consolidadas como para compreender e formar teorias sobre temas emergentes (Snow \& Ketchen, 2014). É nesse aspecto que o trabalho de construção tipológica aqui realizado encontra relevância.

A construção de tipologias consiste em atividade mais complexa que a criação de esquemas de classificaçáo. Essa construção passa pela identificação das dimensôes relevantes, seguida da especificação dos tipos ideais, visando à compreensão e explicação de fenômenos (Niknazar \& Bourgault, 2017). São três as abordagens mais recorrentes: (a) proposiçáo baseada em uma teoria; (b) proposição baseada em contínuos; e (c) proposição baseada em recursos estatísticos (Doty \& Glick, 1994). No presente trabalho, optou-se pelo desenvolvimento tipológico baseado em contínuos da teoria da regulação.

Para a construção da presente tipologia buscou-se identificar inicialmente as apariçóes do tema na literatura 
de administração, assim como já feito em estudos anteriores de tipologia, como em Miles, Snow, Meyer e Coleman (1978). No referido trabalho, os autores desenvolveram sua tipologia com amostra de 16 editoras de livros universitários, justificando que assim conseguiriam abarcar o pensamento em relação às formas organizacionais presentes na indústria. Com base nessa abordagem, os autores identificaram quatro tipos ideais de organizações (prospecção, defensoras, analisadoras e reatoras).

Baseado nessa perspectiva de desenvolvimento tipológico, o presente trabalho realizou revisão dos trabalhos sobre o tema com intuito de servir como ponto inicial para a construção da tipologia. A partir dessa revisão foram analisadas as apariçóes do tema enforcement anticorrupção utilizando análise temática. A tipologia aqui proposta é contextualizada com fundamento na análise temática e com base nas tipologias de enforcement da literatura de regulação. Essa abordagem é consistente com outros trabalhos que desenvolvem tipologias dentro de esquemas teóricos (Niknazar \& Bourgault, 2017).

\section{PROCEDIMENTOS METODOLÓGICOS}

Na presente seção serão apresentadas as consideraçóes metodológicas que permitiram a identificação dos tipos de enforcement anticorrupçáo presentes na literatura de administração. Para tanto, discutem-se a forma de seleção dos trabalhos utilizados para análise e a técnica de análise temática aplicada.

\section{Seleção dos trabalhos}

Para a seleção dos trabalhos, recorreu-se à pesquisa na base de dados Web of Science utilizando combinações das palavras corrupt $t^{*}$ enforcement. Esses termos foram pesquisados no tópico, que considera título, resumo e palavras-chave. Desse parâmetro, resultaram 673 publicaçóes. Em seguida, restringiuse a pesquisa a periódicos das áreas de economics, business, public administration, business finance e management publicados até 2017. Esse filtro resultou em 121 publicações. Na sequência, foram selecionados apenas artigos, resultando em 87 trabalhos. Cabe citar que esse tipo de recorte metodológico, bem como a utilização da referida base de dados, é recorrente em trabalhos de revisão da literatura de administração (Crossan \& Apaydin, 2010).

Desses 87 trabalhos, foi realizada a leitura dos resumos. Foram eliminados os artigos em que corrupção e enforcement eram relacionados apenas como variáveis independentes para descrever o ambiente de negócios nacional, sem que houvesse consideraçóes teóricas relacionando as duas variáveis. Também foram eliminados artigos que apresentavam apenas a evolução da legislação ou de organizaçôes relacionadas ao combate à corrupção. Depois desse filtro inicial, restaram 31 artigos.
Utilizando a base de referências desses 31 artigos na Web of Science, foi realizada uma análise de cocitação através do software VOSviewer para identificar as principais referências relacionadas aos artigos. Essas referências foram utilizadas para consubstanciar a análise temática dos 31 artigos selecionados.

\section{Análise temática}

A análise temática é um método para identificar, analisar e interpretar padróes de significados (temas) em dados qualitativos (Clarke \& Braun, 2017). Essa técnica pode ser dividida em duas vertentes: top-down e bottom-up. Na vertente top-down, o objetivo é definir temas informados pela teoria e aplicá-los aos dados. Na vertente bottom-up, o objetivo é desenvolver indutivamente os temas a partir dos dados (King, 2012). Dessa forma, é possível dizer que a abordagem top-down possui orientação analítica de caráter objetivista e a bottomup orientaçấo exploratória de caráter subjetivista (Clarke \& Braun, 2017).

$\mathrm{Na}$ literatura de administração é possível identificar uma série de aplicaçóes dessa técnica para analisar as mais diversas fontes de dados. De forma ilustrativa, cabe citar alguns trabalhos que, como na presente pesquisa, aplicaram essa técnica a dados documentais. Radcliffe (2013), por exemplo, utilizou-se da análise temática em diários de casais para analisar padróes de decisão na vida familiar. Conaway e Wardrope (2010) utilizaram a análise temática para identificar os tópicos mais comuns em relatórios de administração publicados por empresas. Lane, Koka e Pathak (2002) aplicaram análise temática a artigos para mapear os principais tópicos de pesquisa sobre capacidade absortiva das organizaçóes.

Da mesma forma, essa técnica pode servir para uma diversidade de finalidades, entre elas subsidiar a criação de tipologias. É exemplo de trabalho nesse sentido o de Jabareen (2006), que utilizou análise temática para identificar uma tipologia na literatura de formas urbanas sustentáveis. De maneira semelhante, Kusyk e Lozano (2007) utilizaram análise temática para identificar uma tipologia de responsabilidade social corporativa para pequenas e médias empresas. Por fim, Caza (2012) utilizou a técnica para identificar uma tipologia de oito domínios da discrição organizacional.

\section{Procedimento de análise}

Com relação ao método de aplicação, na literatura são encontradas diversas variaçóes. Uma síntese dessas variaçóes é apresentada por King e Brooks (2018), que classificam as análises temáticas em quatro estilos: (a) análise de template, (b) análise reflexiva, (c) análise de framework e (d) análise de matriz. Dos quatro estilos citados, a análise reflexiva é bottomup e as demais são top-down. Em função do caráter exploratório indutivo buscado no presente trabalho, optou-se por utilizar a 
abordagem reflexiva, que tem como seus maiores expoentes Braun e Clarke (2006).

As autoras propóem o desenvolvimento da análise em seis estágios, que são discutidos e contextualizados a seguir:

1. Familiarização com os dados: $O$ pesquisador deve mergulhar nos dados e buscar familiarizar-se com eles (Clarke \& Braun, 2013). Essa fase foi realizada com a leitura integral dos 31 artigos selecionados para análise.

2. Geração inicial de categorias (codificação): $\mathrm{Na}$ análise reflexiva, ao invés de tentar enquadrar os dados em códigos provenientes de temas preexistentes, o objetivo é utilizar os códigos como guias para tentar encontrar temas subjacentes (Braun \& Clarke, 2006). Para tanto, é possível a busca semântica, focada em significados explícitos, ou a busca latente, focada em conceitos implícitos (Terry, Hayfield, Clarke, \& Braun, 2017). A presente pesquisa utilizou as categorias (contínuos) de enforcement (coercitivo versus persuasivo; público versus privado; formal versus informal) como guias de análise e classificação dos textos e busca de significados latentes.

Nesse ponto, cabe dizer que embora a presente pesquisa tenha utilizado uma codificação teórica como guia, em vez de uma codificação indutiva, a formação dos temas se deu de forma indutiva. Isso porque os códigos provenientes da teoria serviram para agrupar textos semelhantes, e não para enquadrá-los em temas previamente definidos, como seria em uma análise do tipo template. Esse tipo de abordagem da codificação teórica é recomendável quando há um interesse teórico específico do pesquisador (Braun \& Clarke, 2006), como no caso em questáo, em que se buscou compreender os temas de enforcement em administração sob o prisma da teoria da regulação.

Nessa etapa, os textos foram impressos e categorizados manualmente e de forma independente por dois pesquisadores. Depois dessa etapa inicial, as classificaçōes foram confrontadas e discutidas até chegar-se a uma classificação final. Esse procedimento foi adotado em função de ser uma das estratégias sugeridas pela literatura para aprimorar o processo e assegurar a confiabilidade da codificação (Crabtree \& Miller, 1999).
Cabe mencionar que embora exista uma série de softwares disponíveis para análise temática, como NVivo e Atlas TI, com funcionalidades principalmente para a realizaçâo da análise temática do tipo template, que guarda certa semelhança com uma análise de conteúdo, eles não foram utilizados na pesquisa. Essa opção se deu porque a análise temática pretendida não teve como foco a exploração textual propriamente dita, mas sim a observaçáo de códigos latentes. Além disso, o volume de textos não se mostrou tão extenso a ponto de ser imprescindível a utilização de software de análise.

3. Procura por temas: O foco é analisar os códigos levando em consideraçáo como eles são combinados, de modo a formar temas abrangentes (Braun \& Clarke, 2006). Na presente pesquisa, a análise dos códigos conduziu à identificação de quatro grupos de textos com características homogêneas.

4. Revisão dos temas: Objetiva-se verificar se os possíveis temas guardam homogeneidade interna $\mathrm{e}$ heterogeneidade externa, ou seja, se os códigos estão adequadamente atribuídos e os temas possuem um núcleo comum que os torna iguais e os distingue dos demais (Braun \& Clarke, 2006). Isso foi feito pela revisão dos códigos, bem como pela busca de uma linha condutora que fizesse os temas ganharem unicidade.

5. Nomeação dos temas: Nessa etapa, o autor deve questionarse sobre qual a essência de cada tema e, dessa forma, construir um nome conciso, contundente e informativo para cada um deles (Terry et al., 2017). Nessa etapa foram analisados os mecanismos centrais de cada tema e a partir deles foram especificados quatro tipos de enforcement. punitivo, competitivo, de mercado e cultural. Na tabela a seguir é apresentada a alocação dos 31 artigos selecionados na base Web of Knowledge segundo os quatro temas identificados.

6. Produção do relatório: Essa etapa consiste em tecer uma narrativa analítica e contextualizada da literatura sobre as temáticas identificadas (Clarke \& Braun, 2013). Isso é feito no tópico seguinte, no qual os quatro tipos são detalhados.

Tabela 2. Distribuição temática dos estudos sobre enforcement anticorrupção na área de administração.

\begin{tabular}{|c|c|c|c|c|}
\hline \multirow{2}{*}{ Temáticas } & \multirow{2}{*}{ Teórico } & \multicolumn{2}{|c|}{ Teórico empírico } & \multirow[b]{2}{*}{ Total } \\
\hline & & Qualitativo & Quantitativo & \\
\hline Enforcement punitivo & 5 & 0 & 4 & 9 \\
\hline Enforcement de mercado & 1 & 1 & 6 & 8 \\
\hline Enforcement competitivo & 2 & 2 & 3 & 7 \\
\hline Enforcement cultural & 1 & 2 & 4 & 7 \\
\hline Total geral & 9 & 5 & 17 & 31 \\
\hline
\end{tabular}

Nota. Fonte: da pesquisa. 
Além desse roteiro de aplicação da técnica, que consiste em estrutura de trabalho amplamente aceita na literatura, também é possível encontrar recomendações adicionais para assegurar a qualidade da pesquisa. Nesse sentido, King e Brooks (2018) recomendam que em análise temática seja utilizada ao menos uma de três estratégias: comparação intercodificador, feedback de respondentes ou trilhas de auditoria. Na condução da pesquisa, utilizou-se a comparação intercodificador na etapa de geraçáo de categorias e na etapa de revisão dos temas.

\section{TIPOLOGIAS DE ENFORCEMENT}

$\mathrm{Na}$ sequência, serão apresentadas as quatro modalidades de enforcement identificadas a partir da análise temática da literatura de administração.

\section{Enforcement punitivo}

A primeira abordagem para o problema da corrupçáo organizacional tem origem nos trabalhos sobre economia do crime. Nessa linha, busca-se modelar os incentivos para o comportamento criminoso com base na probabilidade de detecção e puniçáo do crime, bem como no valor da punição (Becker, 1968). Assim, quanto maior a probabilidade de detecçáo ou quanto maiores as puniçóes, menores sáo os incentivos para o agente econômico envolver-se em atividades criminosas. Os trabalhos mostram, por exemplo, que o aumento da intensidade de auditoria ou dos valores das multas tem como consequência a redução dos níveis de sonegação fiscal (Chen, 2003) ou reduçấo nos valores contratuais (Di Tella \& Schargrodsky, 2003). Também, quando os níveis de punição são mais severos, tende-se a diminuir o nível de cooperaçáo entre os agentes envolvidos em esquemas de corrupção (Abbink, Irlenbusch, \& Renner, 2002).

Por outro lado, a detecção e a punição geram custos orçamentários, já que envolvem a contratação de mais agentes de enforcement para monitorar e processar os agentes criminosos, bem como maiores gastos para a administração do sistema penitenciário. Assim, dentro dessa linha, o nível ótimo de enforcement consiste em minimizar os incentivos para o crime, sujeito às restriçôes orçamentárias (Polinsky \& Shavell, 2007). Isso implica que a sociedade irá conviver com um nível de crime ideal, já que os malefícios causados por aquele crime náo compensariam os custos envolvidos em sua repressão.

A literatura tem apontado uma série de soluções para tentar otimizar esse trade-off entre enforcement e orçamento. Com relação à probabilidade de detecção, propóe-se aumentar os incentivos para os agentes de enforcement serem mais produtivos, ou terceirizar o sistema de enforcement para o setor privado (Becker \& Stigler, 1974). Em ambos os casos, pode-se chegar a uma situação de aplicação excessiva de enforcement, inclusive com incentivos para que os agentes de enforcement processem inocentes a fim de aumentar suas recompensas.

Já com relação à punição, propóe-se como solução alternar penas privativas de liberdade por penas monetárias, uma vez que as últimas teriam o mesmo efeito inibidor, mas não envolveriam custos com administração do sistema prisional (Polinsky \& Shavell, 2001). Por outro lado, argumenta-se que a substituição de uma pena privativa de liberdade por uma pena monetária, em vez de inibir o comportamento, no caso da corrupçáo, simplesmente faria com que se buscassem valores maiores de corrupção, a fim de compensar as penalidades maiores.

Não bastassem os problemas envolvidos com as restriçóes orçamentárias, ainda há a possibilidade de que haja corrupção dos próprios agentes de enforcement (Becker \& Stigler, 1974). Nessa linha, os agentes econômicos buscarão oferecer propina para que os agentes de enforcement não realizem a detecção das práticas desviantes. A propensão para o oferecimento de propina é tâo maior quanto maiores forem os benefícios obtidos com a corrupção.

Assim, há a necessidade de criação de mecanismos que garantam um sistema de enforcement que não seja corrupto. Nessa linha, seria possível conceber sistemas que incentivassem o agente a ser honesto, ou sistemas que punissem o agente de enforcement pelo comportamento corrupto. A puniçáo tem um limite, pois quando ela ultrapassa a remuneração ou a renda do agente, ela não tem mais efeito. E essa é a realidade de países em desenvolvimento (Rose-Ackerman, 2010). Além disso, a punição para o fiscal cria um desincentivo ao monitoramento, diminuindo a probabilidade de que ele encontre comportamentos desviantes (Mookherjee \& Png, 1995).

De outro lado, propóe-se o aumento na recompensa do agente de enforcement para evitar a cooptação por agentes corruptores do setor privado. Nessa linha, defende-se que inclusive haja remuneraçóes maiores para os agentes de enforcement, a fim de que se atraiam pessoas honestas para essa atividade (Acemoglu \& Verdier, 1998). Se a remuneração dos agentes de enforcement for menor do que a de outros setores, a funçáo de enforcement tenderá a atrair pessoas que veem na corrupçáo uma forma de complementar a diferença salarial (Kugler, Verdier, \& Zenou, 2005). Além disso, a remuneração tem sido associada a maiores taxas de detecção. Nessa linha, trabalhos empíricos mostram que a elevaçáo da remuneração reduz os níveis de corrupção, principalmente na fase de monitoramento (Di Tella \& Schargrodsky, 2003). A opção por maiores remuneraçóes, contudo, demanda maiores recursos orçamentários, o que nem sempre está disponível. 
Além da restrição orçamentária típica, em que a sociedade opta por não investir mais recursos nos órgãos de enforcement, há a possibilidade de restrição orçamentária forçada por interesses de grupos organizacionais envolvidos com corrupçáo, que fazem lobby para que haja redução do orçamento do enforcement (Damania, Fredriksson, \& Mani, 2004), principalmente quando este é atuante.

Por fim, embora seja possível a mudança comportamental dolado organizacional (Abbink et al., 2002), a característica típica do sistema de enforcement punitivo é gerar uma mudança temporária de comportamento: uma vez cessados os esforços de monitoramento, retornam os comportamentos corruptos anteriormente inibidos.

\section{Enforcement de mercado}

Uma segunda alternativa para o enforcement é a atuação do mercado como agente de pressão social para garantir o cumprimento da lei. Nesse sentido, mesmo inexistindo relaçôes contratuais formais ou um agente público coercitivo que garanta o cumprimento de um dever legal, há mecanismos sociais como pressóes sociais, ostracismo e reputação, que fazem com que as obrigaçóes sejam cumpridas (Macaulay, 1963). Essas forças podem decorrer de pressóes individuais e coletivas (Kandori, 1992) e são tanto maiores quanto mais recorrentes forem as interaçóes entre dois agentes (Klein \& Leffler, 1981; Williamson, 1979). Dentro dessa linha, são discutidos dois mecanismos: a recompensa pela integridade e o aumento da transparência.

A recompensa pela integridade tem como princípio criar um contraponto aos benefícios que uma empresa pode receber com a corrupçáo. Nesse sentido, a empresa deixaria de se envolver em corrupção na medida em que o mercado reconhecesse a empresa como honesta e decidisse premiá-la por esse comportamento (O’Higgins, 2006). Essa premiação pela honestidade pode se operacionalizar de várias formas: pelos acionistas que reconhecem a empresa como mais honesta e que, assim, pagam um prêmio na compra de açóes; pelas instituiçóes financeiras, que enxergam clientes não corruptos como de menor risco de crédito e, por decorrência, oferecem menores custos de captação de recursos; ou pelo governo, que cria incentivos para empresas que adotam práticas anticorrupção e não possuem histórico de envolvimento com escândalos de corrupção.

Pesquisas empíricas mostram que as empresas são sensíveis a essas pressóes de mercado em decisões de envolver-se em esquemas de corrupção e que isso se reflete nas políticas de divulgação (Healy \& Serafeim, 2016). Inclusive nos códigos de ética e de medidas anticorrupção aparece um detalhamento operacional das políticas adotadas em frequência muito superior a de outros códigos empresariais, como o ambiental e de trabalho, denotando a maior preocupação com a implementação de tais códigos (Gordon \& Miyake, 2001).

Nessa linha, surgem discussões sobre o modelo ideal de certificação das práticas anticorrupção, para que o mercado não seja enganado por açóes meramente simbólicas (Pierce \& Toffel, 2013). É possível que a certificação seja voluntária ou obrigatória, havendo autocertificação ou certificação por um terceiro, com custos de certificação arcados pelas empresas honestas ou pelas empresas infratoras. O modelo de certificação obrigatória por terceiros, com custos arcados pelas empresas com más práticas, é tido como o mais eficiente (Baksi \& Bose, 2007).

Também há literatura que recomenda o aumento da transparência, tanto pública quanto privada, como meio de aumentar a probabilidade de que desvios sejam identificados pelo mercado. Nessa linha, maior acesso da população à internet e leis de transparência estão associados à redução dos índices de corrupção (Elbahnasawy, 2014). O mesmo acontece com divulgação de renda e patrimônio dos servidores públicos (Gong, 2011).

Por outro lado, a certificação de empresas limpas e a maior transparência possuem efeitos muito limitados se não acompanhadas por uma mudança cultural por parte do mercado, no sentido de desenvolver hábitos de monitoramento e de recompensar empresas não corruptas (Larbi, 2007).

Há também evidências de que existe complementariedade entre enforcement punitivo e enforcement de mercado. Nessa linha, os estudos mostram que após a punição de atos de fraudes por órgãos governamentais, há melhoria no nível informacional e redução do nível de gerenciamento de lucros (Fan, Guan, Li, \& Yang, 2014). Essa melhoria é uma tentativa de compensar os efeitos negativos que a punição recebida gera nos modelos de avaliação utilizados por acionistas e órgãos de financiamento, já que nesses modelos há uma tendência de descontar o risco associado a eventos futuros de corrupçáo no cálculo do valor presente (Healy \& Serafeim, 2016).

Por fim, há trabalhos comparando modelos de enforcement punitivo e enforcement pelo mercado. Os resultados mostram que a supervisáo direta, em geral, não está associada com redução nos níveis de corrupçáo. Já o modelo de supervisão pelo mercado, com o agente governamental supervisionando apenas a política de disclosure, está associado a maior redução nos níveis de corrupçáo (Beck, Demirgüç-Kunt, \& Levine, 2006). Para justificar esses resultados, argumenta-se que a supervisão direta está sujeita à captura regulatória e a supervisão pelo mercado náo. 


\section{Enforcement competitivo}

É possível conceber uma terceira abordagem para o enforcement a partir da estrutura de competiçáo do mercado (Svensson, 2005). Argumenta-se que se todas as empresas competissem em um livre mercado, em função das pressóes exercidas pela concorrência, os lucros das empresas diminuiriam, fazendo com que náo houvesse espaço para pagamento de propinas (Otáhal, 2014). Nesse sentido, os estudos mostram que há maiores níveis de pagamento de propinas em países com baixos níveis de competição ou com maior intervenção do governo na economia (Clarke \& Xu, 2004).

Há, contudo, certa controvérsia na relação de causalidade entre competição e corrupção. Alguns trabalhos apontam o aumento da competitividade como consequência de ambientes menos corruptos. Assim, a reduçáo do poder dos burocratas em relaçáo à imposição de restrições de mercado faria com que houvesse menores oportunidades de extração de rendas para exploraçáo de serviços públicos, dando mais espaço para a competição (Emerson, 2006). Da mesma forma, a redução dos níveis de corrupção faria com que houvesse maiores incentivos para que empresas se formalizassem e adotassem tecnologia da informação, aumentando assim sua competitividade (Sudhir \& Talukdar, 2015).

Além do mais, em ambientes em que a corrupção é disseminada, náo existiria vantagem econômica efetiva para que empresas se engajassem em atividades corruptas, de modo que o pagamento de propina representaria um custo que afetaria a competitividade empresarial (Fadahunsi \& Rosa, 2002). Nessa linha, os trabalhos mostram que a aprovação de leis anticorrupção empaísescommaiores níveisdecorrupçãonãogeraefeitosnegativos na competitividade da indústria (Geo-Jala \& Mangum, 2000), o que sugere que não haveria vantagem econômica com a corrupção para as empresas antes da aprovação dessas leis.

Já outros trabalhos mostram a competitividade como variável interveniente no processo de redução da corrupção. Nesse sentido, os trabalhos apontam que a exposição à competição internacional, medida pelo total de importaçóes, faz com que haja uma redução nos níveis de corrupção do país (Ades \& Di Tella, 1999). Da mesma forma, empresas domésticas que desejam ingressar em uma competiçáo em mercados internacionais que sejam menos corruptos precisam reduzir suas exposiçóes a atividades corruptas para tornarem-se mais competitivas e evitar danos a suas imagens (Pierre, 2015).

Outros trabalhos, embora não tratando diretamente da relação entre corrupção e competitividade, trazem evidências que apontam para menor tolerância empresarial a ambientes corruptos à medida que as condiçóes de mercado se tornam mais restritivas. Nessa linha, as evidências mostram que à medida que as empresas necessitam do enforcement público para dar efetividade a seus contratos ou necessitam de acesso ao mercado de crédito, há uma pressão para que elas se formalizem, o que faz com que elas estejam mais sujeitas a práticas de extorsão por parte dos burocratas públicos (Sarte, 2000). Essa maior exposição faz com que a corrupção passe a ganhar uma dimensão social maior, afetando um contingente maior de empresas, o que pode desencadear açóes políticas do meio empresarial para reduzir a discricionariedade do agente público.

Essa maior exposição ao setor público também guarda relação com o nível de enforcement punitivo, já que à medida que aumentam os níveis de fiscalização e punição das atividades informais, aumenta também a tendência de formalização das empresas (Antunes \& Cavalcanti, 2007; Fisman \& Miguel, 2007; Sukiassyan \& Nugent, 2008).

\section{Enforcement cultural}

Uma quarta modalidade de enforcement provém dos estudos sobre cultura. Dentro de uma perspectiva organizacional, entende-se cultura como uma programação coletiva da mente que distingue os membros de uma categoria dos membros de outra categoria (Hofstede \& Minkov, 2010). O comportamento dentro dos padróes de conduta compartilhados é adquirido através de processos de socializaçáo e se torna um bem valorizado pelo indivíduo pertencente àquela cultura, de modo que a quebra desse valor representa um custo moral ao indivíduo (Greif, 1994). Esse valor atribuído a um padrão de conduta atua como mecanismo indutor ou inibidor de comportamento.

Uma linha de estudos busca comparar indivíduos que foram criados em ambientes distintos, mas que convivem em um mesmo ambiente econômico e institucional. Nesse sentido, destaca-se o trabalho de Fisman e Miguel (2007), que analisaram o número de infraçóes de trânsito cometidas em Nova York por diplomatas. Os autores verificaram que os indivíduos provenientes de países mais corruptos tendiam a praticar mais delitos do que agentes provenientes de países menos corruptos.

Outra linha busca realizar experimentos com grupos de pessoas a fim de identificar variaçôes nos comportamentos. Nessa linha, Shaw, Katsaiti e Pecoraro (2015) buscaram entender aspectos comportamentais ligados ao envolvimento de alunos em corrupçáo. Os autores verificaram que a percepção do ato como sendo corrupto e a prévia participaçáo do sujeito em outros atos de corrupção são fatores que explicam o comportamento corrupto.

Há estudos que atribuem essa cultura de corrupção a segmentos específicos da populaçáo (Sööt, 2012), assim como também há estudos que buscam identificar elementos da cultura organizacional como associados ao comportamento desviante. Nessa linha, as evidências apontam que organizaçóes privadas, em função da orientação mais agressiva para o lucro, tendem a apresentar comportamentos desviantes em frequência maior do que organizaçôes do terceiro setor (Becker, Kessler, \& McClellan, 2005). 
Ainda, empresas que atuam em ambientes com vazios institucionais ou baixa regulamentaçáo tendem a desenvolver uma cultura de informalidade, em que a troca de favores e o oferecimento de vantagens são vistos como formas de estreitar os laços e aumentar a certeza das operações (Verbeke \& Kano, 2013). Da mesma forma, em ambientes em que prevalece a reciprocidade entre os indivíduos há maior incidência de corrupção (Alon \& Hageman, 2017).

Por outro lado, nas empresas em que há cultura de impessoalidade e de profissionalismo há menor tolerância à corrupção. Nessa linha, em empresas pequenas, por haver uma cultura fortemente ligada à figura do fundador, a tendência é haver maiores níveis de corrupçáo do que em empresas de grande porte, onde prevalece a cultura de profissionalismo (DeBacker, Heim, \& Tran, 2015). Da mesma forma, agentes de empresas multinacionais, que geralmente apresentam maior grau de profissionalismo, tendem a apresentar comportamentos corruptos em frequência inferior ao de empregados de empresas domésticas, que tendem a ser menos profissionalizadas que as multinacionais (Braguinsky \& Mityakov, 2015).

Os estudos tambémapontamasorganizaçóes comoagentes capazes de implementar práticas que alteram percepçóes culturais a respeito da corrupção. Assim, a mera existência de um comitê de ética, mesmo que não efetivo, serve como meio simbólico capaz de modificar a percepção dos agentes organizacionais sobre a tolerância organizacional a práticas de corrupção (Smith, 2003). Ainda, a profissionalização da empresa, através da contratação de empregados provenientes de multinacionais com uma forte cultura de transparência, atua como mecanismo capaz de alterar a cultura organizacional de empresas domésticas através de um processo de socialização (Braguinsky \& Mityakov, 2015).

\section{CONEXÕES ENTRE AS LITERATURAS DE REGULAÇÃO E DE ADMINISTRAÇÃO}

$\mathrm{Na}$ seção anterior foram identificadas quatro formas em que o termo enforcement vem sendo empregado na literatura de organizaçôes. Da exposição realizada é possível perceber que elas apresentam fundamentos diferentes, tanto em termos de características de enforcement quanto em relação aos mecanismos pelos quais elas induzem o comportamento. Além disso, em uma perspectiva de stakeholder é possível inferir que essas formas de enforcement apresentam ligaçōes mais fortes com determinados agentes de interesse. Uma sistematização das características dessas abordagens é apresentada a seguir.

Tabela 3. Comparativo das modalidades de estudo relacionado a enforcement na área de organizaçôes.

\begin{tabular}{|c|c|c|c|c|}
\hline Tipologia de enforcement & Enforcement punitivo & Enforcement competitivo & Enforcement de mercado & Enforcement cultural \\
\hline Definição & $\begin{array}{l}\text { Indução de conformidade } \\
\text { baseada em uma atuaçáo } \\
\text { punitiva. }\end{array}$ & $\begin{array}{l}\text { Indução de conformidade } \\
\text { baseada na busca por } \\
\text { eficiência. }\end{array}$ & $\begin{array}{l}\text { Indução de conformidade } \\
\text { baseada em restriçóes de } \\
\text { recursos. }\end{array}$ & $\begin{array}{l}\text { Indução de conformidade } \\
\text { por alinhamento moral ao } \\
\text { padráo de conduta. }\end{array}$ \\
\hline Mecanismo de atuação & $\begin{array}{l}\text { - Penalidade } \\
\text { - Fiscalizaçáo }\end{array}$ & $\begin{array}{l}\text { - Eficiência de produção } \\
\text { - Acesso a mercados }\end{array}$ & $\begin{array}{l}\text { - Volume de recursos } \\
\text { financeiros } \\
\text { - Prêmio de honestidade }\end{array}$ & $\begin{array}{l}\text { - Crenças e valores } \\
\text { - Processos de socialização }\end{array}$ \\
\hline Estratégia de enforcement & Coercitivo & Coercitivo & Persuasivo & Persuasivo \\
\hline Agente de enforcement & Público e privado & Privado & Privado & Privado \\
\hline Relação de enforcement & Formal & Informal & Informal & Informal \\
\hline Stakeholder envolvido & $\begin{array}{l}\text { - Governo } \\
\text { - Agências reguladoras }\end{array}$ & $\begin{array}{l}\text { - Competidores } \\
\text { - Clientes }\end{array}$ & $\begin{array}{l}\text { - Acionistas } \\
\text { - Bancos }\end{array}$ & $\begin{array}{l}\text { - Funcionários } \\
\text { - Gestores }\end{array}$ \\
\hline
\end{tabular}

Nota. Fonte: elaboração própria.

Com relação a essa classificação, é possível fazer algumas consideraçôes. Em primeiro lugar, considerando a estratégia de enforcement, é possível inferir, pela recorrência dos argumentos levantados, que dentro das abordagens competitiva e punitiva há uma tendência de abordar o enforcement em uma perspectiva de coercitividade, ao passo que nas abordagens de mercado e cultural há maior recorrência de abordagens persuasivas. Já em relação à formalidade, o enforcement punitivo tende a apresentar uma característica mais formal, ao passo que o competitivo, o cultural e de mercado tendem a apresentar uma perspectiva mais informal. Essa perspectiva se assemelha a outras abordagens da literatura (Armour, 2008; Frank, 1984). Assim, em uma associação das literaturas de administraçáo e regulação, é possível apresentar a seguinte relação.

Tabela 4. Relação entre enforcement na literatura de administração e na literatura de regulação.

\begin{tabular}{ccc}
\hline EstratégialRelação & Coercitivo & Persuasivo \\
\hline Formal & Punitivo & -- \\
Informal & Competitivo & Mercado; Cultural \\
\hline
\end{tabular}

Nota. Fonte: elaboraçáo própria. 
Outro ponto que merece destaque é que na literatura de administração há uma predominância de trabalhos com enfoque privado, havendo uma associação do enforcement público ao enforcement punitivo. Essa perspectiva parece reforçar a ideia de que na literatura há uma tentativa de buscar abordagens menos dependentes do orçamento governamental (Batory, 2012). Outra explicação para essa relação pode estar associada ao fato de que em administração busca-se uma perspectiva que contemple diversos agentes (stakeholders), não focando apenas em uma distinção entre o público e o privado (Freeman, 1984).

\section{DISCUSSÃO GERAL}

No presente trabalho buscou-se situar o emprego da terminologia enforcement em estudos de administração dentro da perspectiva da teoria de enforcement proveniente da literatura de regulação. Para tanto, inicialmente foram identificadas as dimensóes relacionadas ao enforcement na literatura de regulaçáo, seguindo com a identificação das linhas teóricas relacionadas ao enforcement anticorrupção nos estudos organizacionais, e finalizando com uma discussão das inter-relaçóes entre essas duas literaturas.

Como resultado, foi possível identificar quatro tipos distintos do termo enforcement na área de administração, os quais possuem características díspares do ponto de vista das dimensōes de enforcement da literatura de regulação. Desse modo, conseguiu-se atingir o objetivo proposto. A evidenciação dessas características contribui para o melhor emprego da terminologia nos estudos aplicados, como também aponta para possíveis caminhos para ampliação da literatura.

Nesse sentido, a partir do presente trabalho, estudos futuros podem buscar desenvolver teorias que relacionem os tipos de enforcement identificados com fenômenos organizacionais como desempenho financeiro, legitimidade, custos de transação, cultura organizacional, entre outras possibilidades. Outro caminho para estudos futuros está na investigação de medidas de quantificação das dimensōes de enforcement identificadas no presente estudo a fim de mensurar o grau de ocorrência de cada tipo de enforcement e subsidiar trabalhos empíricos. Por fim, estudos empíricos podem testar a efetividade de cada um dos tipos de enforcement identificados no presente estudo com intuito de oferecer orientaçóes para aplicaçóes práticas no ambiente corporativo.

Ainda, cabe destacar que há uma crescente busca de modelos mentais alternativos, que busquem entender o comportamento do agente não apenas em uma perspectiva racional utilitarista, mas também institucional e cultural (Fisman \& Miguel, 2007). Nesse sentido, mostra-se como promissor investigar abordagens comportamentais, que ainda são estudos residuais e mais recentes em relação ao enforcement punitivo. Além dessa perspectiva, o presente trabalho enseja algumas linhas possíveis de avanço teórico empírico.
Uma possibilidade de investigação baseada nessa sistematizaçâo consiste em analisar em que medida essas dimensóes se complementam ou mostram-se como rivais. Há trabalhos, por exemplo, que apontam para a influência recíproca entre as estratégias de coercitividade e as de persuasão (Liu et al., 2018). Essa perspectiva pode ser ampliada para investigar, por exemplo, em que medida o grau de formalidade pode impactar na propensão de adoção informal de uma prática anticorrupção, ou entáo como o modelo punitivo associa-se com o modelo cultural.

Outra possibilidade de investigação consiste em analisar os custos associados a cada abordagem, com intuito de realizar uma análise de custo/benefício das diversas perspectivas (Cohen, 2000). Isso porque embora sejam claros os custos orçamentários de uma abordagem coercitiva pública, também é necessário considerar que há custos associados às abordagens privadas de enforcement, tal como custos de agência, custos de transação e até mesmo custos de implementação de estratégias de monitoramento.

Como última sugestão, considerando agentes com múltiplas racionalidades, é possível investigar em que grau essas diversas abordagens interagem conjuntamente na determinação do comportamento dos agentes (Glicksman \& Earnhart, 2006). Nesse sentido, seria interessanteinvestigar se aspectos contextuais podem fazer com que uma ou outra abordagem esteja mais presente no ambiente e tenha maior grau de efetividade sobre a formação de comportamentos.

Finalmente, cabe destacar que o presente estudo de classificação tipológica, assim como qualquer estudo dessa natureza, apresenta como principal limitação a abordagem teórica utilizada, que contribuiu para a forma final dos tipos de enforcement identificados. Essa limitaçáo, contudo, não invalida o estudo, uma vez que apresenta a perspectiva sob um prisma de análise. Estudos futuros podem, dentro de outras abordagens teóricas, propor alternativas tipológicas para o mesmo problema de pesquisa, com as quais se possa contrastar a presente tipologia.

\section{NOTA}

1. São traduções diretas do termo enforcement para o português: execução, coação, imposição, constrangimento. Em inglês, no entanto, esse termo tem um significado mais abrangente, sendo, normalmente, sinônimo do processo de indução da obediência de uma norma. Dessa forma, dentre as opçóes possíveis, não se vislumbra nenhum termo que tenha significado equivalente no português. Em função disso, no presente texto, é utilizado o termo do inglês. 


\section{REFERÊNCIAS}

Abbink, K., Irlenbusch, B., \& Renner, E. (2002). An experimental bribery game. Journal of Law, Economics, and Organization, 18(2), 428-454. https://doi.org/10.1093/jleo/18.2.428

Acemoglu, D., \& Verdier, T. (1998). Property rights, corruption and the allocation of talent: A general equilibrium approach. The Economic Journal, 108(450), 1381-1403. https://doi.org/10.1111/1468-0297.00347

Ades, A., \& Di Tella, R. (1999). Rents, competition, and corruption. The American Economic Review, 89(4), $982-$ 993. https://doi.org/10.1257/aer.89.4.982

Alon, A., \& Hageman, A. M. (2017). An institutional perspective on corruption in transition economies. Corporate Governance: An International Review, 25(3), 155-166. https://doi.org/10.1111/corg.12199

Antunes, A. R., \& Cavalcanti, T. (2007). Start up costs, limited enforcement, and the hidden economy. European Economic Review, 51(1), 203-224. https://doi.org/10.1016/j.euroecorev.2005.11.008

Armour, J. (2008). Enforcement strategies in UK corporate governance: A roadmap and empirical assessment. In A. M. Pacces (Ed.), The law and economics of corporate governance (Chap. 5). Cheltenham, UK: Edward Elgar Publishing.

Ashforth, B. E., Gioia, D. A., Robinson, S. L., \& Trevino, L. K. (2008). Re-viewing organizational corruption. Academy of Management Review, 33(3), 670-684. https://doi.org/10.5465/amr.2008.32465714

Bacharach, S. B. (1989). Organizational theories: Some criteria for evaluation. The Academy of Management Review, 14(4), 496-515. https://doi.org/10.2307/258555

Bakos, Y., \& Dellarocas, C. (2011). Cooperation without enforcement? A comparative analysis of litigation and online reputation as quality assurance mechanisms. Management Science, 57(11), 1944-1962. https://doi.org/10.1287/mnsc. 1110.1390

Baksi, S., \& Bose, P. (2007). Credence goods, efficient labelling policies, and regulatory enforcement. Environmental and Resource Economics, 37(2), 411-430. https://doi.org/10.1007/s10640-006-9032-0

Batory, A. (2012). Why do anti-corruption laws fail in Central Eastern Europe? A target compliance perspective. Regulation \& Governance, 6(1), 66-82. https://doi.org/10.1111/j.1748-5991.2011.01125.x

Beck, T., Demirgüç-Kunt, A., \& Levine, R. (2006). Bank supervision and corruption in lending. Journal of Monetary Economics, 53(8), 2131-2163. https://doi.org/10.1016/j.jmoneco.2005.10.014

Becker, D., Kessler, D., \& McClellan, M. (2005). Detecting medicare abuse. Journal of Health Economics, 24(1), 189210. https://doi.org/10.1016/j.jhealeco.2004.07.002

Becker, G. S. (1968). Crime and punishment: An economic approach. Journal of Political Economy, 76(2), 169-217. Retrieved from http://www.jstor.org/stable/1830482
Becker, G. S., \& Stigler, G. J. (1974). Law enforcement, malfeasance, and compensation of enforcers. The Journal of Legal Studies, 3(1), 1-18. https://doi.org/10.1086/467507

Braguinsky, S., \& Mityakov, S. (2015). Foreign corporations and the culture of transparency: Evidence from Russian administrative data. Journal of Financial Economics, 117(1), 139-164. https://doi.org/10.1016/j.jfineco.2013.02.016

Braun, V., \& Clarke, V. (2006). Using thematic analysis in psychology. Qualitative Research in Psychology, 3(2), 77 101. https://doi.org/10.1191/1478088706qp063oa

Braun,V., \&Clarke,V.(2016).(Mis)conceptualising themes, thematic analysis, and other problems with Fugard and Potts'(2015) sample-size tool for thematic analysis. International Journal of Social Research Methodology, 19(6), 739-743. https://doi.org/10.1080/13645579.2016.1195588

Burbank, S. B., Farhang, S., \& Kritzer, H. M. (2013). Private enforcement. Lewis o Clark Law Review, 17, 637-722. Retrieved from https://scholarship.law.umn.edu/faculty articles/1

Burrel, G. (2006). Ciência normal, paradigmas, metáforas, discursos e genealogia da análise. In S. Clegg, C. Hardy, W. Nord (Eds.), Handbook de estudos organizacionais: Modelos de análise e novas questóes em estudos organizacionais (Chap. 17, pp. 437-460). Sáo Paulo: Atlas

Carr, I. (2007). Corruption, legal solutions and limits of law. International Journal of Law in Context, 3(3), 227-255. https://doi.org/10.1017/S1744552307003035

Carson, L. D., \& Prado, M. M. (2014). Mapping corruption \& its institutional determinants in Brazil [IRIBA Working Paper nr. 8]. International Research Initiative on Brazil and Africa, Manchester, UK. Retrieved from http://www. brazil4africa.org/wp-content/uploads/publications/working papers/IRIBA WP08 Mapping Corruption and its Institutional Derminants in Brazil.pdf

Caza, A. (2012). Typology of the eight domains of discretion in organizations. Journal of Management Studies, 49(1), 144177.

Chen, B.-L. (2003). Tax evasion in a model of endogenous growth. Review of Economic Dynamics, 6(2), 381-403. https://doi.org/10.1016/S1094-2025(03)00002-4

Clarke, G. R. G., \& Xu, L. C. (2004). Privatization, competition, and corruption: How characteristics of bribe takers and payers affect bribes to utilities. Journal of Public Economics, 88(9-10), 2067-2097. https://doi.org/10.1016/j.jpubeco.2003.07.002

Clarke, V., \& Braun, V. (2013). Teaching thematic analysis: Overcomingchallengesanddevelopingstrategiesforeffective learning. The Psychologist, 26(2), 120-123. Retrieved from http://www.thepsychologist.org.uk/archive/archive home. cfm?volumeID=26\&editionID=222\&ArticleID=2222

Clarke, V., \& Braun, V. (2017). Thematic analysis. The Journal of Positive Psychology, 12(3), 297-298. https://doi.org/10.1080/17439760.2016.1262613 
Cohen, M. A. (2000). Empirical research on the deterrent effect of environmental monitoring and enforcement. Environmental Law Reporter News and Analysis, 30(4), 10245-10252. Retrieved from http://www.oecd.org/environment/outreach/33947732.pdf

Conaway, R. N., \& Wardrope, W. J. (2010). Do their words really matter? Thematic analysis of US and Latin American CEO letters. International Journal of Business Communication, 47(2), 141-168. https://doi.org/10.1177\%2F0021943610364523

Crabtree, B. F., \& Miller, W. L. (1999). Doing qualitative research. Thousand Oaks, CA: Sage Publications.

Crossan, M. M., \& Apaydin, M. (2010). A multidimensional framework of organizational innovation: A systematic review of the literature. Journal of Management Studies, 47(6), 1154-1191. https://doi.org/10.1111/j.1467-6486.2009.00880.x

Damania, R., Fredriksson, P. G., \& Mani, M. (2004). The persistence of corruption and regulatory compliance failures: Theory and evidence. Public Choice, 121(3), 363390. https://doi.org/10.1007/s11127-004-1684-0

DeBacker, J., Heim, B. T., \& Tran, A. (2015). Importing corruption culture from overseas: Evidence from corporate tax evasion in the United States. Journal of Financial Economics, 117(1), 122-138. https://doi.org/10.1016/j.jfineco.2012.11.009

Delbridge, R., \& Fiss, P. C. (2013). Editors' comments: Styles of theorizing and the social organization of knowledge. Academy of Management Review, 38(3), 325-331. https://doi.org/10.5465/amr.2013.0085

Di Tella, R., \& Schargrodsky, E. (2003). The role of wages and auditing during a crackdown on corruption in the city of Buenos Aires. The Journal of Law and Economics, 46(1), 269-292. https://doi.org/10.1086/345578

Doty, D. H., \& Glick, W. H. (1994). Typologies as a unique form of theory building: Toward improved understanding and modeling. Academy of Management Review, 19(2), 230251. https://doi.org/10.5465/amr.1994.9410210748

Earnhart, D. H., \& Glicksman, R. L. (2015). Coercive vs. cooperative enforcement: Effect of enforcement approach on environmental management. International Review of Law and Economics, 42, 135-146. https://doi.org/10.1016/j.irle.2015.02.003

Elbahnasawy, N. G. (2014). E-government, internet adoption, and corruption: An empirical investigation. World Development, 57, 114-126. https://doi.org/10.1016/j.worlddev.2013.12.005

Ellickson, R. C. (1998). Law and economics discovers social norms. The Journal of Legal Studies, 27(S2), 537-552. https://doi.org/10.1086/468033

Emerson, P. M. (2006). Corruption, competition and democracy. Journal of Development Economics, 81(1), 193-212. https://doi.org/10.1016/j.jdeveco.2005.04.005

Fadahunsi, A., \& Rosa, P. (2002). Entrepreneurship and illegality: Insights from the Nigerian cross-border trade. Journal of Business Venturing, 17(5), 397-429. https://doi.org/10.1016/S0883-9026(01)00073-8
Fan, J. P., Guan, F., Li, Z., \& Yang, Y. G. (2014). Relationship networks and earnings informativeness: Evidence from corruption cases. Journal of Business Finance \& Accounting, 41(7-8), 831-866. https://doi.org/10.1111/jbfa.12078

Fisman, R., \& Miguel, E. (2007). Corruption, norms, and legal enforcement: Evidence from diplomatic parking tickets. Journal of Political Economy, 115(6), 1020-1048. https://doi.org/10.1086/527495

Fiss, P. C. (2011). Building better causal theories: A fuzzy set approach to typologies in organization research. Academy of Management Journal, 54(2), 393-420. https://doi.org/10.5465/amj.2011.60263120

Frank, N. (1984). Policing corporate crime: A typology of enforcement styles. Justice Quarterly, 1(2), 235-251. https://doi.org/10.1080/07418828400088131

Freeman, R. E. (1984). Strategic management: A stakeholder approach. Boston: Pitman.

Galang, R. M. N. (2012). Victim or victimizer: Firm responses to government corruption. Journal of Management Studies, 49(2), 429-462. https://doi.org/10.1111/j.1467-6486.2010.00989.x

Galbiati, R., \& Vertova, P. (2014). How laws affect behavior: Obligations, incentives and cooperative behavior. International Review of Law and Economics, 38, 48-57. https://doi.org/10.1016/j.irle.2014.03.001

Garoupa, N., \& Klerman, D. M. (2010). Corruption and private law enforcement: Theory and history. Review of Law \& Economics, 6(1), 75-96. Retrieved from https://ideas.repec.org/a/bpj/rlecon/v6y2010i1n3.html

Geo-Jala, M. A., \& Mangum, G. L. (2000). The foreign corrupt practices act's consquences for US trade: The Nigerian example. Journal of Business Ethics, 24(3), 245-255. https://doi.org/10.1023/A:1006025226862

Gioia, D. A., \& Pitre, E. (1990). Multiparadigm perspectives on theory building. Academy of Management Review, 15(4), 584-602. https://doi.org/10.5465/amr.1990.4310758

Glicksman, R. L., \& Earnhart, D. H. (2006). Depiction of the regulator-regulated entity relationship in the chemical industry: Deterrence-based vs. cooperative enforcement. William \& Mary Environmental Law and Policy Review, 31(3), 603-660. Retrieved from https://scholarship.law.wm.edu/wmelpr/vol31/iss3/2

Gong, T. (2011). An 'institutional turn' in integrity management in China. International Review of Administrative Sciences, 77(4), 671-686. https://doi.org/10.1177\%2F0020852311419391

Gordon, K., \& Miyake, M. (2001). Business approaches to combating bribery: A study of codes of conduct. Journal of Business Ethics, 34(3), 161-173. https://doi.org/10.1023/A:1012517622479 
Gormley, W. T., Jr. (1998). Regulatory enforcement styles. Political Research Quarterly, 51(2), 363-383. https://doi.org/10.1177\%2F106591299805100204

Gray, W. B., \& Shimshack, J. P. (2011). The effectiveness of environmental monitoring and enforcement: A review of the empirical evidence. Review of Environmental Economics andPolicy, 5(1),3-24.https://doi.org/10.1093/reep/req017

Greif, A. (1994). Cultural beliefs and the organization of society: A historical and theoretical reflection on collectivist and individualist societies. Journal of Political Economy, 102(5), 912-950. https://doi.org/10.1086/261959

Gunningham, N. (2010). Enforcement and compliance strategies. In R. Baldwin, M. Cave, M. Lodge (Eds.), The Oxford handbook of regulation. Oxford: Oxford University Press.

Hay, J. R., \& Shleifer, A. (1998). Private enforcement of public laws: A theory of legal reform. The American Economic Review, 88(2), 398-403. Retrieved from https://www.jstor.org/stable/116955

Healy, P. M., \& Serafeim, G. (2016). An analysis of firms' selfreported anticorruption efforts. The Accounting Review, 91(2), 489-511. https://doi.org/10.2308/accr-51191

Heeks, R., \& Mathisen, H. (2012). Understanding success and failure of anti-corruption initiatives. Crime, Law and Social Change, 58(5), 533-549. https://doi.org/10.1007/s10611-011-9361-y

Helland, E. (1998). The enforcement of pollution control laws: Inspections, violations, and self-reporting. Review of Economics and Statistics, 80(1), 141-153. https://doi.org/10.1162/003465398557249

Hofstede, G. J., \& Minkov, M. (2010). Cultures and Organizations: Software for the Mind (3rd ed.) New York: McGraw-Hill Education.

Jabareen, Y. R. (2006). Sustainable urban forms: Their typologies, models, and concepts. Journal of Planning Education and Research, 26(1), 38-52. https://doi.org/10.1177\%2F0739456X05285119

Jia, C., Ding, S., Li, Y., \& Wu, Z. (2009). Fraud, enforcement action, and the role of corporate governance: Evidence from China. Journal of Business Ethics, 90(4), 561-576. https://doi.org/10.1007/s10551-009-0061-9

Kaczmarek, S. C., \& Newman, A. L. (2011). The long arm of the law: Extraterritoriality and the national implementation of foreignbriberylegislation. InternationalOrganization, 65(4), 745-770. https://doi.org/10.1017/S0020818311000270

Kagan, R. A. (1989). Editor's introduction: Understanding regulatory enforcement. Law \& Policy, 11(2), 89-119. https://doi.org/10.1111/j.1467-9930.1989.tb00022.x

Kandori, M. (1992). Social norms and community enforcement. The Review of Economic Studies, 59(1), 63-80. https://doi.org/10.2307/2297925

Katou, A. A. (2013). The relationship between corrupt practices and organisational performance: An empirical investigation. International Journal of Business Governance and Ethics, 8(4), 323-347. https://doi.org/10.1504/IJBGE.2013.059162
King, N. (2012). Doing template analysis. In G. Symon, C. Cassell (Eds.), Qualitative organizational research: Core methods and current challenges (pp. 77-101). Thousand Oaks, CA: SAGE Publications.

King, N., \& Brooks, J. (2018). Thematic analysis in organisational research. In C. Cassell, A. L. Cunliffe, G. Grandy (Eds.), The SAGE handbook of qualitative business and management research methods: Methods and challenges (Chap. 14). Thousand Oaks, CA: SAGE Publications.

Kirchler, E. (1999). Reactance to taxation: Employers' attitudes towards taxes. The Journal of Socio-Economics, 28(2), 131 138. https://doi.org/10.1016/S1053-5357(99)00003-7

Klein, B., \& Leffler, K. B. (1981). The role of market forces in assuring contractual performance. Journal of Political Economy, 89(4), 615-641. https://doi.org/10.1086/260996

Kube, S., \& Traxler, C. (2011). The interaction oflegal and social norm enforcement. Journal of Public Economic Theory, 13(5), 639660. https://doi.org/10.1111/j.1467-9779.2011.01515.x

Kugler, M., Verdier, T., \& Zenou, Y. (2005). Organized crime, corruption and punishment. Journal of Public Economics, 89(9-10), 1639-1663. https://doi.org/10.1016/j.jpubeco.2004.05.005

Kusyk, S. M., \& Lozano, J. M. (2007). SME social performance: a four-cell typology of key drivers and barriers on social issues and their implications for stakeholder theory. Corporate Governance, 7(4), 502-515. https://doi.org/10.1108/14720700710820588

Lane, P. J., Koka, B., \& Pathak, S. (2002). A thematic analysis and criticalassessmentofabsorptivecapacity research. Proceedings of the Academy of Management Annual Meeting, Denver, CO. https://doi.org/10.5465/apbpp.2002.7516527

Lange, D. (2008). A multidimensional conceptualization of organizational corruption control. Academy of Management Review, 33(3), 710-729. https://doi.org/10.5465/amr.2008.32465742

Larbi, G. A. (2007). Between spin and reality: Examining disclosure practices in three African countries. Public Administration and Development, 27(3), 205-214. Retrieved from https:// etico.iiep.unesco.org/en/resource/between-spin-and-realityexamining-disclosure-practices-three-african-countries

Linstead, S., Maréchal, G., \& Griffin, R. W. (2014). Theorizing and researching the dark side of organization. Organization Studies, 35(2), 165-188. https://doi.org/10.1177\%2F0170840613515402

Liu, N., Van Rooij, B., \& Lo, C. W.-H. (2018). Beyond deterrent enforcement styles: Behavioural intuitions of Chinese environmental law enforcement agents in a context of challenging inspections. Public Administration, 96(3), 497-512. https://doi.org/10.1111/padm.12415

Luo, Y. (2005). An organizational perspective of corruption. Management and Organization Review, 1(1), 119-154. https://doi.org/10.1111/j.1740-8784.2004.00006.x

Macaulay, S. (1963). Non-contractual relations in business: A preliminary study. American Sociological Review, 28(1), 55-67. https://doi.org/10.2307/2090458 
Matitz, Q. R. S., \& Vizeu, F. (2012). Construção e uso de conceitos em estudos organizacionais: Por uma perspectiva social e histórica. Revista de Administraçâo Pública, 46(2), 577-598. https://doi.org/10.1590/S0034-76122012000200011

May, P., \& Burby, R. (1998). Making sense out of regulatory enforcement. Law \& Policy, 20(2), 157-182. https://doi.org/10.1111/1467-9930.00046

McAllister, L. K. (2010). Dimensions of enforcement style: Factoring in regulatoryautonomyand capacity. Law \& Policy, 32(1),6178. https://doi.org/10.1111/j.1467-9930.2009.00308.x

Miles, R. E., Snow, C. C., Meyer, A. D., \& Coleman, H. J. (1978). Organizational strategy, structure, and process. Academy of Management Review, 3(3), 546-562. https://doi.org/10.5465/amr.1978.4305755

Mintzberg, H. (1979). The structuring of organizations: A synthesis of the research. Upper Saddle River, NJ: Prentice-Hall

Mooi, E. A., \& Gilliland, D. I. (2013). How contracts and enforcement explain transaction outcomes. International Journal of Research in Marketing, 30(4), 395-405. https://doi.org/10.1016/j.ijresmar.2013.04.003

Mookherjee, D., \& Png, I. P.-L. (1995). Corruptible law enforcers: How should they be compensated? The Economic Journal, 105(248), 145-159. https://doi.org/10.2307/2235324

Niknazar, P., \& Bourgault, M. (2017). Theories for classification vs. classification as theory: Implications of classification and typology for the development of project management theories. International Journal of Project Management, 35(2), 191-203. https://doi.org/10.1016/j.ijproman.2016.11.002

Osuagwu, L. (2012). Conceptualization of corruption in business organizations. American International Journal of Contemporary Research, 2(5), 18-25. Retrieved from http://www.aijcrnet.com/journal/index/185

Otáhal, T. (2014). Mises, Hayek and corruption. Journal of Business Ethics, 119(3), 399-404. https://doi.org/10.1007/s10551-013-1646-x

O'Higgins, E. R. (2006). Corruption, underdevelopment, and extractive resource industries: Addressing the vicious cycle. Business Ethics Quarterly, 16(2), 235-254. https://doi.org/10.1017/S1052150X00012823

Pertiwi, K. (2018). Contextualizing corruption: A crossdisciplinary approach to studying corruption in organizations. Administrative Sciences, 8(2), 12. https://doi.org/10.3390/admsci8020012

Pierce, L., \& Toffel, M. W. (2013). The role of organizational scope and governance in strengthening private monitoring. Organization Science, 24(5), 1558-1584. https://doi.org/10.1287/orsc.1120.0801

Pierre, N. (2015). Foreign direct investment: Rule of law and corruption. Asia-Pacific Journal of Financial Studies, 44(2), 281-297. https://doi.org/10.1111/ajfs.12089
Pinto, J., Leana, C. R., \& Pil, F. K. (2008). Corrupt organizations or organizations of corrupt individuals? Two types of organization-level corruption. Academy of Management Review, 33(3), 685-709. https://doi.org/doi/10.2307/20159431

Polinsky, A. M., \& Shavell, S. (2000). The economic theory of public enforcement of law. Journal of Economic Literature, 38(1), 45-76. https://doi.org/10.1257/jel.38.1.45

Polinsky, A. M., \& Shavell, S. (2001). Corruption and optimal law enforcement. Journal of Public Economics, 81(1), 1-24. https://doi.org/10.1016/S0047-2727(00)00127-4

Polinsky, A. M., \& Shavell, S. (2007). The theory of public enforcement of law. In A. M. Polinsky \& S. Shavell (Eds.), Handbook of Law And Economics (Chap. 6, pp. 403-454). Amsterdam: North Holland.

Porter, M. E. (1980). Competitive strategy: Techniques for analyzing industries and competition. New York: Free Press.

Posner, E. A. (2002). Law and social norms. Cambridge: MA: Harvard University Press.

Radcliffe, L. S. (2013). Qualitative diaries: Uncovering the complexities of work-life decision-making. Qualitative Research in Organizations and Management: An International Journal, 8(2). 163-180. http://doi.org/10.1108/qrom-04-2012-1058

Rechtschaffen, C. (1997). Deterrence vs. cooperation and the evolving theory of environmental enforcement. Southern California Law Review, 71(6), 1181-1272.

Rose-Ackerman, S. (2010). The law and economics of bribery and extortion. Annual Review of Law and Social Science, 6, 217-238. https://doi.org/10.1146/annurev-lawsocsci-102209-152942

Sarte, P.-D. G. (2000). Informality and rent-seeking bureaucracies in a model of long-run growth. Journal of Monetary Economics, 46(1), 173-197. https://doi.org/10.1016/S0304-3932(00)00020-9

Shaw, P., Katsaiti, M. S., \& Pecoraro, B. (2015). On the determinants of educational corruption: The case of Ukraine. Contemporary Economic Policy, 33(4), 698-713. https://doi.org/10.1111/coep.12097

Shepherd, C., \& Challenger, R. (2013). Revisiting paradigm(s) in management research: A rhetorical analysis of the paradigm wars. International Journal of Management Reviews, 15(2), 225-244. https://doi.org/10.1111/ijmr.12004

Smith, R. W. (2003). Enforcement or ethical capacity: Considering the role of state ethics commissions at the millennium. Public Administration Review, 63(3), 283-295. https://doi.org/10.1111/1540-6210.00290

Snow, C. C., \& Ketchen, D. J., Jr. (2014). Typology-driven theorizing: A response to Delbridge and Fiss. Academy of Management Review, 39(2), 231-233. https://doi.org/10.5465/amr.2013.0388

Sudhir, K., \& Talukdar, D. (2015). The "Peter Pan syndrome" in emerging markets: The productivity-transparency tradeoff in IT adoption. Marketing Science, 34(4), 500-521. https://doi.org/10.1287/mksc.2015.0921 
Sukiassyan, G., \& Nugent, J. B. (2008). Associations versus registration as alternative strategies of small firms. Small Business Economics, 31(2), 147-161. https://doi.org/10.1007/s11187-007-9085-7

Sööt, M.-L. (2012). The role of management in tackling corruption. Baltic Journal of Management, 7(3), 287-301. https://doi.org/10.1108/17465261211245463

Svensson, J. (2005). Eight questions about corruption. The Journal of Economic Perspectives, 19(3), 19-42. https://doi.org/10.1257/089533005774357860

Terry, G., Hayfield, N., Clarke, V., \& Braun, V. (2017). Thematic analysis. In W. S. Rogers, \& C. Willig (Eds.), The SAGE Handbook of Qualitative Research in Psychology (2nd ed., pp. 17-37). London: SAGE Publications

Torsello, D., \& Venard, B. (2016). The anthropology of corruption. Journal of Management Inquiry, 25(1), 34-54. https://doi.org/10.1177\%2F1056492615579081

\section{Autoria}

\section{Robson Fernandes Soares*}

Universidade Positivo, Programa de Mestrado e Doutorado em Administração

R. Prof. Pedro Viriato Parigot de Souza, no 5300, Campo Comprido, 81280-330, Curitiba, PR, Brasil.

E-mail: robsoares88@gmail.com

(1) https://orcid.org/0000-0003-0890-9078

\section{Edson Ronaldo Guarido Filho}

Universidade Positivo, Programa de Mestrado e Doutorado em Administração

R. Prof. Pedro Viriato Parigot de Souza, no 5300, Campo Comprido, 81280-330, Curitiba, PR, Brasil.

E-mail: edson.guarido@gmail.com

(1) https://orcid.org/0000-0001-7905-1596

* Autor Correspondente

\section{Financiamento}

Os autores relataram que náo houve suporte financeiro para pesquisa deste artigo.

\section{Conflito de Interesses}

Os autores informaram que não há conflito de interesses.

\section{Verificação de Plágio}

A RAC mantém a prática de submeter todos os documentos aprovados para publicação à verificação de plágio, mediante o emprego de ferramentas específicas, e.g.: iThenticate.
Verbeke, A., \& Kano, L. (2013). The transaction cost economics (TCE) theory of trading favors. Asia Pacific Journal of Management, 30(2), 409-431. https://doi.org/10.1007/s10490-012-9324-6

Vitell, S. J., \& Hidalgo, E. R. (2006). The impact of corporate ethical values and enforcement of ethical codes on the perceived importance of ethics in business: A comparison of US and Spanish managers. Journal of Business Ethics, 64(1), 31-43. https://doi.org/10.1007/s10551-005-4664-5

Voermans, W. (2014). Motive-based enforcement. Revista Jurídica da Presidência, 16(108), 17-38. https://doi.org/10.20499/2236-3645.RJP2014v16e108-39

Williamson, O. E. (1979). Transaction-cost economics: The governance of contractual relations. The Journal of Law and Economics, 22(2), 233-261. https://doi.org/10.1086/466942

Williamson, O. E. (1996). The mechanisms of governance. Oxford: Oxford University Press.

\section{Contribuições dos Autores}

$1^{\text {a }}$ autor: conceituação (liderança); análise formal (liderança); investigação (liderança); metodologia (liderança); validação (igual); escrita - rascunho original (liderança); escrita revisão e edição (liderança).

$2^{\circ}$ autor: conceituação (suporte); análise formal (suporte); metodologia (suporte); validação (igual); escrita - rascunho original (suporte); escrita - revisão e edição (suporte).

\section{Direitos Autorais}

A RAC detém os direitos autorais deste conteúdo.

\section{Método de Revisão por Pares}

Este conteúdo foi avaliado utilizando o processo de revisão por pares duplo-cego (double-blind peer-review). A divulgação das informaçóes dos pareceristas constantes na primeira página e do Relatório de Revisão por Pares (Peer Review Report) é feita somente após a conclusáo do processo avaliativo, e com o consentimento voluntário dos respectivos pareceristas e autores.

\section{Disponibilidade dos Dados}

A RAC incentiva o compartilhamento de dados mas, por observância a ditames éticos, não demanda a divulgação de qualquer meio de identificação de sujeitos de pesquisa, preservando a privacidade dos sujeitos de pesquisa. A prática de open data é viabilizar a reproducibilidade de resultados, e assegurar a irrestrita transparência dos resultados da pesquisa publicada, sem que seja demandada a identidade de sujeitos de pesquisa. 